\title{
Titania-Platinum Nanobiocatalyst as Treatment for Central Nervous System Tumors: A Case Report on a Pediatric Ependymoma
}

Tessy M. López-Goerne ${ }^{1,2 *}$,Francisco Javier Padilla-Godínez ${ }^{1,3}$, Daniel Álvarez ${ }^{1,4}$ Esteban Gómez ${ }^{5}$ Paola Ramírez ${ }^{1}$ Eduardo Barragán Fernando Chico-Ponce-de-León ${ }^{6}$, Vicente González-Carranza' ${ }^{7}$ Juan Carlos García-Beristain ${ }^{4}$, Pilar Dies-Suárez ${ }^{7}$ and Juan C. Manrique ${ }^{8}$

${ }^{1}$ Department of Health Care, Autonomous Metropolitan University-Xochimilco, Coyoacan, Mexico City, Mexico

${ }^{2}$ Department of Chemical and Biomolecular Engineering, Tulane University, New Orleans, Lousiana, USA

${ }^{3}$ Department of Mathematics and Physics, Western Institute of Technology and Higher Education, Tlaquepaque, Jalisco, Mexico

${ }^{4}$ Department of Neurology, Children's Hospital of Mexico "Federico Gomez", Cuauhtemoc, Mexico City, Mexico

${ }^{5}$ Institute of Physics, Humboldt University of Berlin, Berlin, Germany

${ }^{6}$ Department of Physics and Astronomy, Arizona State University, Tempe, Arizona, USA

${ }^{7}$ Department of Imageology, Children's Hospital of Mexico "Federico Gomez", Cuauhtemoc, Mexico City, Mexico

${ }^{8}$ Faculty of Medicine PET Unit, National Autonomous University of Mexico, Coyoacan, Mexico City, Mexico

*Corresponding author: Tessy M. López-Goerne, Department of Health Care, Autonomous Metropolitan University-Xochimilco, Coyoacan, Mexico City, Mexico, Tel: +52 (1) 551951 5658; E-mail: tessy3@prodigy.net.mx

Received: May 26, 2020; Accepted: June 9, 2020; Published: June 16, 2020

\begin{abstract}
Central nervous system tumors affect the pediatric population in 3.3 to 4.5 cases or every 100,000 children per year, representing the main cause of cancer in children (26\%), only second to leukemia (30\%). Traditional treatments include cytotoxic chemotherapy, nonetheless, platinum-derived compounds widely used as chemotherapeutics, such as cisplatin and carboplatin, are limited by their cumulative nephrotoxicity and neurotoxicity. In this report we synthesized a novel nanobiocatalyst based in platinum stabilized in functionalized titania which had previously exhibited antineoplastic properties with high selectivity. The nanoparticles were tested in an SH-DY5Y cells model and in a pediatric patient with ependymoma. The in vitro test allowed us to study the mechanism of action of the nanobiocatalyst, with the observation of cellular uptake by endocytosis. The nanobiocatalyst triggers catalysis reactions in the C-C and C-N bonds of the DNA present in the mitochondria and the nucleus. After the application of the nanobiocatalyst in the pediatric patient total tumor elimination was observed, as well as general clinical improvement with no signs or symptoms of tumor recurrence and no side effects. The results of this work demonstrate the importance of continuing research in catalytic nanomedicine.
\end{abstract}

Keywords: Catalytic nanomedicine, CNS tumor, Ependymoma, Nanobiocatalyst, Platinum-Titania

\section{Introduction}

Central nervous system (CNS) tumors constitute a heterogeneous group of neoplasms that includes from well-differentiated and relative nonmalignant lesions, such as meningiomas, to highly invasive, undifferentiated lesions, such as multiform glioblastoma [1]. In the pediatric population, CNS tumors occur in 3.3 to 4.5 cases for every 100,000 children per year $[2,3]$, with astrocytic tumors being the most common lesion [4]. These tumors represent the second main cause of cancer in children (26\%), only second to leukemia $(30 \%)[5,6]$. It is currently the leading cause of death from neoplasms in children [5]. Between 1970 and 2012, the rate of mortality was reduced by $76 \%$ for leukemias, while for tumors of the nervous system the percentage of mortality showed a reduction of $31 \%$ [5,7]. About 3 out of 4 children with brain tumors (all types combined) survive at least 5 years after being diagnosed; this number drops to 1 out of 4 in the case of glioblastoma [8]. In Mexico, children in the age group 0-9 years represent the most affected, with a predominance of male patients presenting astrocytoma and medulloblastoma [9]. At the Hospital Infantil de México "Federico Gómez" (HIMFG) the most common cases of CNS tumors are astrocytomas (32\%), medulloblastomas (19\%), craniopharyngiomas (11\%) and ependymomas (10.24\%), with a significant incidence increase between 1970 and 2004 [10].

Traditional treatments for pediatric brain tumors include surgery, radiation, proton beam therapies, radiosurgery, targeted drug therapy, and cytotoxic chemotherapy, the latter reserved for children who have had treatment failure with surgery and radiation therapy [11]. Platinum-derived compounds, such as cisplatin and carboplatin, are widely used as chemotherapeutics in CNS tumors $[12,13]$. However, high dose-platinum therapies are limited by their cumulative nephrotoxicity and neurotoxicity [14]. In 2006, T. López, et al. reported the characterization of a novel nanobiocatalyst formed by functionalized titania network with $1 \%$ of platinum $(\mathrm{NPt})$, this nanodevice showed an important antineoplastic activity, demonstrating, by means of experimental models, that it can cause cell 
death mediated by apoptosis without causing any kind of damage to healthy cells, both locally and systematically $[15,16]$. The HIMFG has approved the application of this therapy as a compassionate treatment for resilient patients in accordance with the Declaration of Helsinki, ClinicalTrials.gov Identifier: NCT03250520. In this article we present a physicochemical and in vivo evaluation of the NPt's properties, as well as a case report of a pediatric ependymoma tumor treated with the nanobiocatalyst. A possible mechanism of the cytotoxic action at the cellular level is also offered.

\section{Methods and Materials}

\section{NPt synthesis}

$\mathrm{Pt}-\mathrm{TiO}_{2}(\mathrm{NPt})$ nanoparticles were obtained through the modified sol-gel method process previously reported [17] patented under WO 2019/017723 A2, using Titanium (IV) butoxide (Sigma-Aldrich, 97\%) as the precursor, acetylacetone (Sigma-Aldrich, 99\%) as the solvent and without hydrolysis catalyst, and distilled water. An appropriate amount of Platinum (II) acetylacetonate (Sigma-Aldrich, 97\%) was dissolved in acetylacetonate in order to obtain a $1 \% \mathrm{~mol}$ of Platinum. Functionalization agents were also added in order to develop an analogy with cells. The sample was dried at $70^{\circ} \mathrm{C}$ and crushed for further analysis.

\section{Electronic microscopy}

Scanning electron microscopy (SEM) was performed in a Hitachi-4800 Field Emission Scanning Microscope operated at $3 \mathrm{kV}$ to investigate porous morphology and nanostructure. The cryogenic conditions were maintained with a constant liquid nitrogen flow through the SEM analysis chamber. The aqueous phase from the top surface of the bubble shape frozen sample was removed by maintaining the temperature gradient $\left(10^{\circ} \mathrm{C}\right)$ for $5 \mathrm{~min}$ between the sample and the anticontamination plate. The sample was then transferred under the protection of a high vacuum into the cryo-FESEM microscope chamber and imaged at an accelerating voltage of $2 \mathrm{kV}$ and at a working distance of 5 to $6 \mathrm{~mm}$. The high magnification Transmission Electron Microscopy (TEM) images were obtained using TEM; JEOL
2010, operated at $120 \mathrm{kV}$ voltage equipped with energy dispersive spectroscopic (EDS) microanalysis system (OXFORD). The images were obtained using a CCD Mega Vision (III) camera.

\section{X-ray photoemission spectroscopy}

The spectra were collected in a VSW Scientific Instrument HA100 with 285 lenses, the excitation source was $\mathrm{Al} \mathrm{Ka}(\mathrm{E}=1486.6 \mathrm{eV})$, the instrument is equipped with spherical sector analyzer; the analyzer pass energy was $22 \mathrm{eV}$ and resolution of $0.6 \mathrm{eV}$. Calibration and reference spectra were taken the same day. A Shirley function was applied for background correction [18].

\section{In vitro antitumor activity in cells}

SH-DY5Y cells were cultured using DMEM containing 10\% FBS, $10000 \mathrm{U}$ penicillin $/ 10 \mathrm{mg} / \mathrm{mL}$ streptomycin at $37^{\circ} \mathrm{C}$ in $5 \% \mathrm{CO}_{2}$ atmosphere. The cells were washed with PBS sterile and added $800 \mathrm{~mL}$ of trypsin (0.05\%, EDTA) for each box. NPt was administered and a in situ transmission electron microscopy was carried out to observe the cells. The material was fixed in $5 \%$ glutaraldehyde in cacodylate buffer $(0.067 \mathrm{M}, \mathrm{pH} 6.2)$ with $0.15 \%$ ruthenium red for 24 hours at $20^{\circ} \mathrm{C}$. The material was then washed five times in the buffer, postfixed in $2 \%$ osmium tetroxide in buffer, washed five more times in the buffer, and dehydrated through a series of acetone washes. The specimen was embedded in low viscosity embedding resin and strained with uranyl acetate and lead citrate, reinforced with evaporated carbon.

\section{In vivo antitumor activity}

The nanoparticles had already been tested in C6 glioma cells in a Wistar rat model, showing tumor elimination and no side effects [17].

\section{Case Report}

The present case is a 7 year and 3 months old right-handed male patient, with no significant family or an allergic background. Starts at the age of 2 years and 3 months with progressive headache and vomiting, after a neuroimaging study, neurologists diagnosed hydrocephalus as a consequence of the presence of a tumor in the posterior fossa (Figure 1a), surgical resection was performed removing

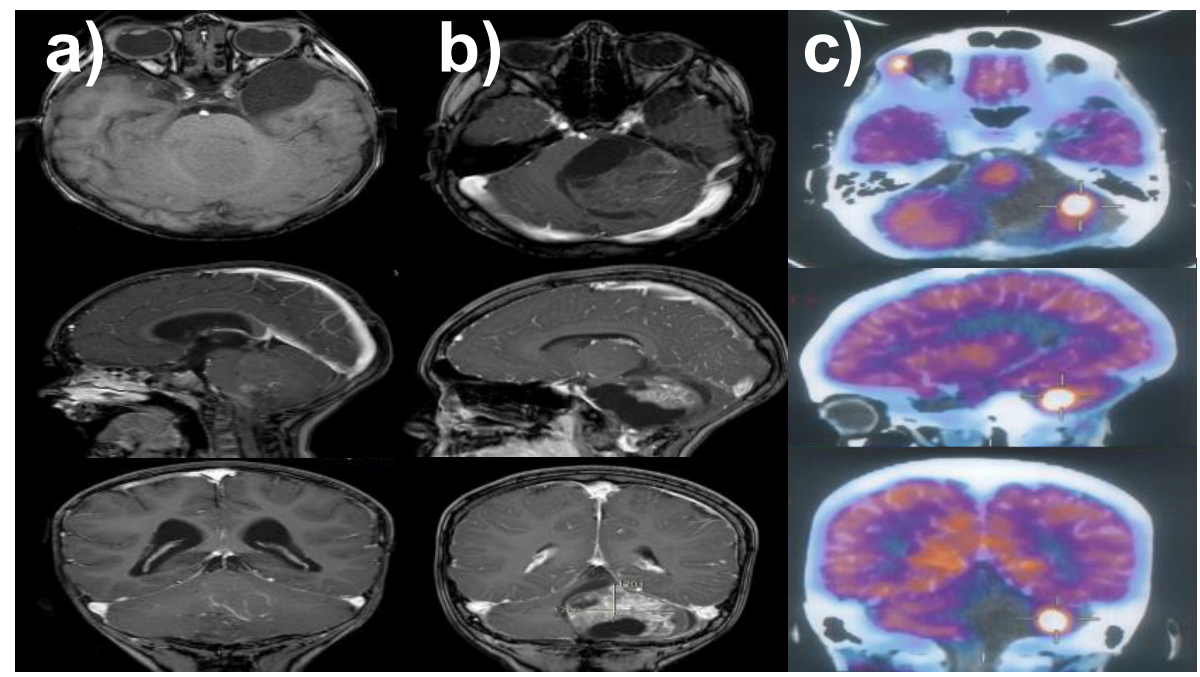

Figure 1: T1 weighted MRI of encephalon with gadolinium; (a) first lesion detected at 2 years and 3 months; (b) first tumor recurrence at 6 years and 2 months; (c) 18-Fluoro-deoxyglucose positron emission tomography (FDG-PET) confirming tumor recurrence at 6 years and 5 months. 
$90 \%$ of the lesion and a ventriculoperitoneal shunt was placed. The histopathological analysis indicates a Classic Ependymoma (WHO grade II). He remained hospitalized for three months, presenting ventriculitis as a complication and therefore, requiring multiple antibiotic treatment schemes. On discharge presented neurological cognitive and motor sequelae, and focal epileptic seizures treated with $30 \mathrm{mg} / \mathrm{kg} /$ day of levetiracetam every 12 hours. After receiving $45 \mathrm{~Gy}$ of radiotherapy on an outpatient basis and neurological rehabilitation, partial recovery of motor and cognitive skills is observed.

When reaching the age of 6 years and 2 months, the mother of the child detected the onset of progressive deviation to the right of labial commissure and difficulty in swallowing of solids associated with alteration in gait. A neurological examination noted right peripheral facial paralysis, deviation of the soft palate to the left, alteration in solids swallowing, left hemibody with dysmetria and dysdiadochokinesia, and posterior opulsion of the march to the left. Tumor recurrence was diagnosed with a lesion in the stem and left cerebellum (Figure 1b). A resection surgery was performed again removing $85 \%$ of the tumor, leading to important neurological sequelae, requiring mechanical ventilation and tracheostomy and gastrostomy, remaining hospitalized for 2 months.

Three months after the last surgical procedure, Magnetic Resonance Imaging (MRI) showed tumoral growth that was later confirmed by 18-Fluoro-deoxyglucose positron emission tomography (FDG-PET) (Figure 2c). The patient required a new surgical procedure, resecting $80 \%$ of the tumoral mass. At this point, the patient presented important neurological sequelae. Histopathological diagnoses indicate a Recurrent Classical Ependymoma (WHO grade II). A 20 Gy of radiotherapy was applied as palliative treatment. Clinically he was alert, active, have adequate interaction with the environment, obeyed simple orders and presented alterations in working memory and attention with moderate intellectual disability, the persistence of left peripheral facial paralysis, alteration in swallowing and left hemispheric cerebellar syndrome with tracheostomy without oxygen and was fed by gastrostomy (he had a Lansky scale of 70). Four months later, the patient presented again tumor recurrence in the brain observed in MRI (Figure 2a). After a joint informative session with the parents, it was decided to use NPt as compassionate treatment, in accordance with the national and international ethical guidelines and the previous agreement to the informed consent from the parents.

\section{Results and Discussion}

Electronic microscopy studies. Electronic microscopy studies were carried out to investigate the morphologic porous nanostructure of the NPt-Ca nanoparticles. SEM images (Figure 3a and $3 \mathrm{~b}$ ) show conglomerate formation with individual diameters of 0.2 to $1.0 \mu \mathrm{m}$. The TEM study (Figure $3 \mathrm{c}$ and $3 \mathrm{~d}$ ) confirmed particle size to be less than $10 \mathrm{~nm}$ in diameter. As expected, $\mathrm{TiO}_{2}$ exhibited a crystalline structure. A profound analysis throughout the nanobiocatalyst did not allow us to identify any point related to platinum nanoparticles. The absence of Pt nanoparticles is caused by the high dispersion and the low concentration of the metal. Nonetheless, when the sample was frozen the small nanoparticles previously observed (1-2 nm) agglomerated into $50 \mathrm{~nm}$-particles, as the platinum in the nonreduced sample was monodisperse. An EDX analysis carried out during the SEM study showed the composition of NPt material (Figure 4). As can be observed, the material is mainly composed of $\mathrm{Ti}$ and $\mathrm{O}$ (due to the $\mathrm{TiO}_{2}$ matrix), $\mathrm{Pt}$ and $\mathrm{C}$. The large amount detected of carbon is due to the presence of acetylacetonate ligands that are forming mono or bidentate ligands with the oxygen atoms of octahedral titania. One the other hand, the different positions observed for Pt and Ti peaks indicate that titania supports platinum with different oxidation states.

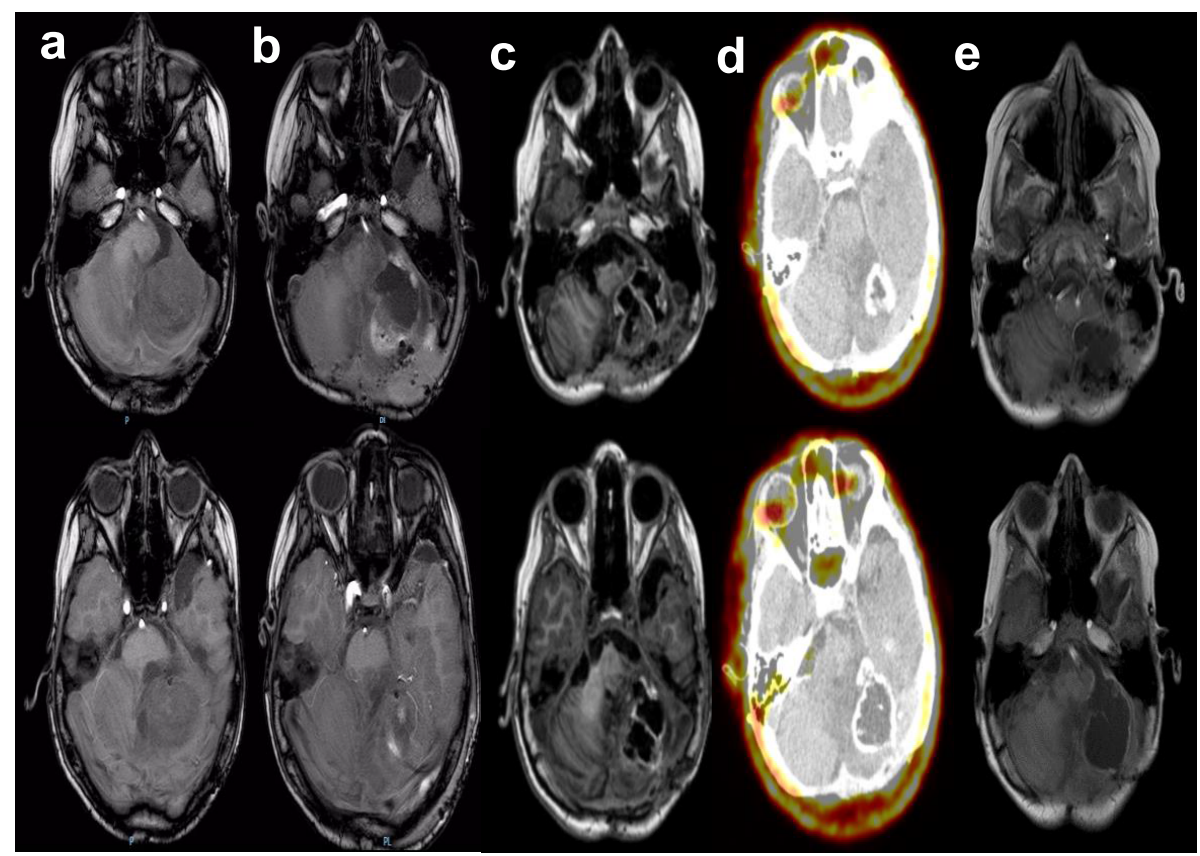

Figure 2: (a, b, c, e) Magnetic resonance imaging in different axial sections of the brain in T1 without gadolinium are observed in the different columns. In column (d) 18F-fluoro-ethyl-Ltyrosine positron emission tomography. From left to right (a) 48 hours prior to placement and post placement (b) 24 hours, (c) 1 month, (d) 3 months and (e) 4 months. 

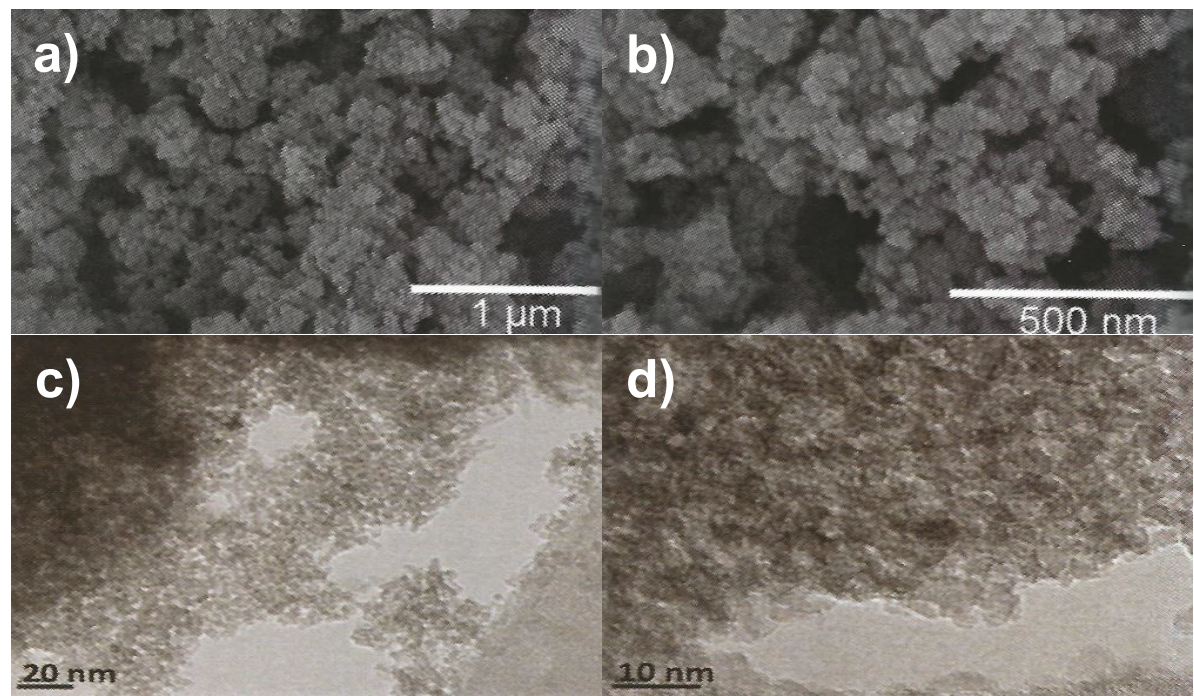

Figure 3: (a, b) SEM and (c, d) TEM images of the NPt nanoparticles. SEM images with a cote of $1 \mu \mathrm{m}$ (a) and $500 \mathrm{~nm}$ (b) show agglomerates with diameters from 0.2 to $1.0 \mu \mathrm{m}$. TEM images with a cote of $20 \mathrm{~nm}$ (c) and $10 \mathrm{~nm}$ (d) confirm particle size to be less than $10 \mathrm{~nm}$ in diameter.

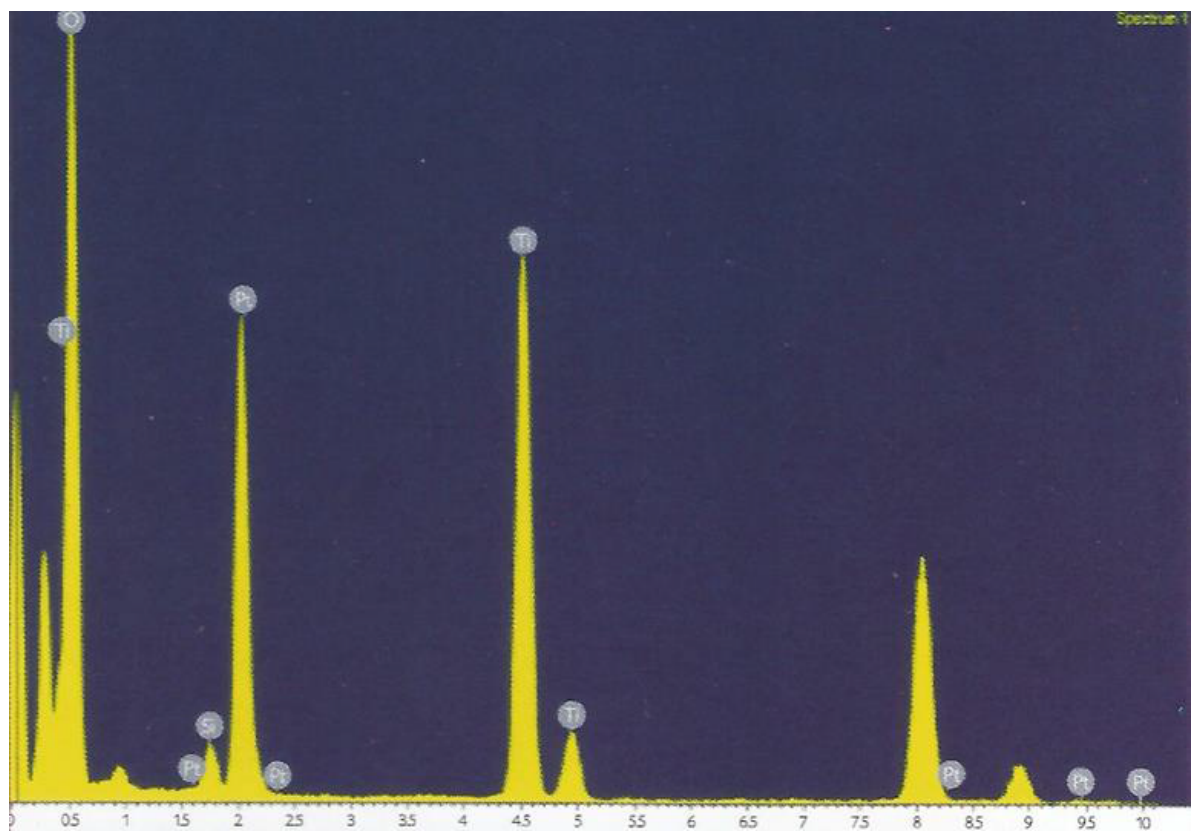

Figure 4: EDS spectrum of the NPt nanoparticles. The appearance of Ti, O, and Pt peaks indicates the presence of the platinum supported in titania. Characteristic peaks of titanium and platinum distributed in different positions of the spectrum indicates platinum stabilized in titania with different oxidation states.

XPS spectra of the NPt nanoparticles are shown in the reference [18]. Due to the main interest in the titania matrix and the supported platinum, special attention was given to these peaks. The Ti $2 \mathrm{p}$ spectrum displays a spin-orbit split of $5.79 \mathrm{eV}$ between the Ti $2 \mathrm{p} 3 / 2$ $(459.67 \mathrm{eV})$ and the Ti $2 \mathrm{p} 1 / 2(465.46 \mathrm{eV})$ peaks related with $\mathrm{Ti}(\mathrm{IV})$ species [18]. The O 1s signal was centered in $532.2 \mathrm{eV}$ with a slight shift from the reported for conventional $\mathrm{TiO}_{2}$ commonly around $530 \mathrm{eV}$ [19]. This signal is formed by two bands located at 531.02 and $532.51 \mathrm{eV}$, indicating two different oxygen species. The first was identified with the Ti-O bond in titania [17] and the last one with oxygen in the carbonyl group of acetylacetonate ligand [20]. In the platinum XPS spectra we show the $4 \mathrm{f} 7 / 2$ and $4 \mathrm{f} 5 / 2$ signals at 74.13 and $77.26 \mathrm{eV}$, correspondingly. The spin-orbit split observed indicates a probable combination of $\mathrm{Pt}(\mathrm{II})$ and $\mathrm{Pt}(\mathrm{IV})$ species [17].

\section{In vitro study}

The obtained nanoparticles were tested in vitro directly with cancer cells (SH-DY5Y cells). A suspension of nanoparticles was incubated directly with the cells and a TEM study was carried out to observe the behavior of the nanoparticles in situ (Figure 5). The internalization mechanism of the nanoparticles is endocytosis (Figure $5 \mathrm{a}-5 \mathrm{c}$ ), specifically pinocytosis, a biological process used by the cell to uptake liquids and macromolecules from the extracellular matrix through vesicles [21].

Our main hypothesis is based on the fact that the functionalization agents in the NPt resemble those found in cellular biology [22-25]. The endocytosis process is believed to be carried out due to a specific ligand-receptor interaction between the functionalization elements 
in the surface of the nanoparticles (possibly phosphate) and an unidentified receptor exclusively found in the cancer cells. This theory is supported by the specificity observed in previous works [26,27], in which the nanoparticles entered in the malignant cells while healthy cells were only surrounded without exhibiting endocytosis. The identification and characterization of such receptor remains in process. Another hypothesis considers the enhanced permeability and retention (EPR) effect observed in the tumor environment, in which liposomes, nanoparticles, and macro-molecular drugs tend to accumulate in tumor tissue much more than they do in normal tissues [28-31]. This phenomenon could induce endocytosis by accumulation. In both theories, nanoparticles exhibit high selectively, entering only cancer cells by means of vesicle uptake.

Nanoparticles surrounding the malignant cell (Figure 5a) start entering the membrane trough vesicle formation (Figure $5 b$ ) and are endocytosed into the cytosol (Figure $5 \mathrm{c}$ ). The vesicle formed exhibits the NPt distributed on its luminal face (Figure 5d), which supports the hypothesis of a ligand-receptor binding. In the cytosol, vesicles travel through the intracellular matrix (Figure $5 \mathrm{e}$ and $5 \mathrm{f}$ ) and disintegrate liberating the nanoparticles in the intracellular matrix (Figure 5g-5i), where they pursue two objectives: the mitochondrial crest and the nuclear membrane (Figure $5 \mathrm{j}$-5l). This behavior can be explained in terms of the acidity of the deoxyribonucleic acid (DNA) present in both the nucleus and the mitochondria, which makes these organelles highly reactive to the nanoparticles. The main targets of the NPt are the phosphodiester bonds and the nitrogen bases, which present available electron pairs that allow them to be adsorbed by the nanobiocatalyst's surface [15]. The nanoparticles then carry out a catalytic reaction breaking the $\mathrm{C}-\mathrm{C}$ and $\mathrm{C}-\mathrm{N}$ bonds in the molecules involved, hence modifying the structure of the DNA. These transformations initiate a signaling pathway that ends up in the death of the cell (apoptosis) [32]. In Figure 5k and $5 \mathrm{l}$ a mitochondrion is observed to be filled with
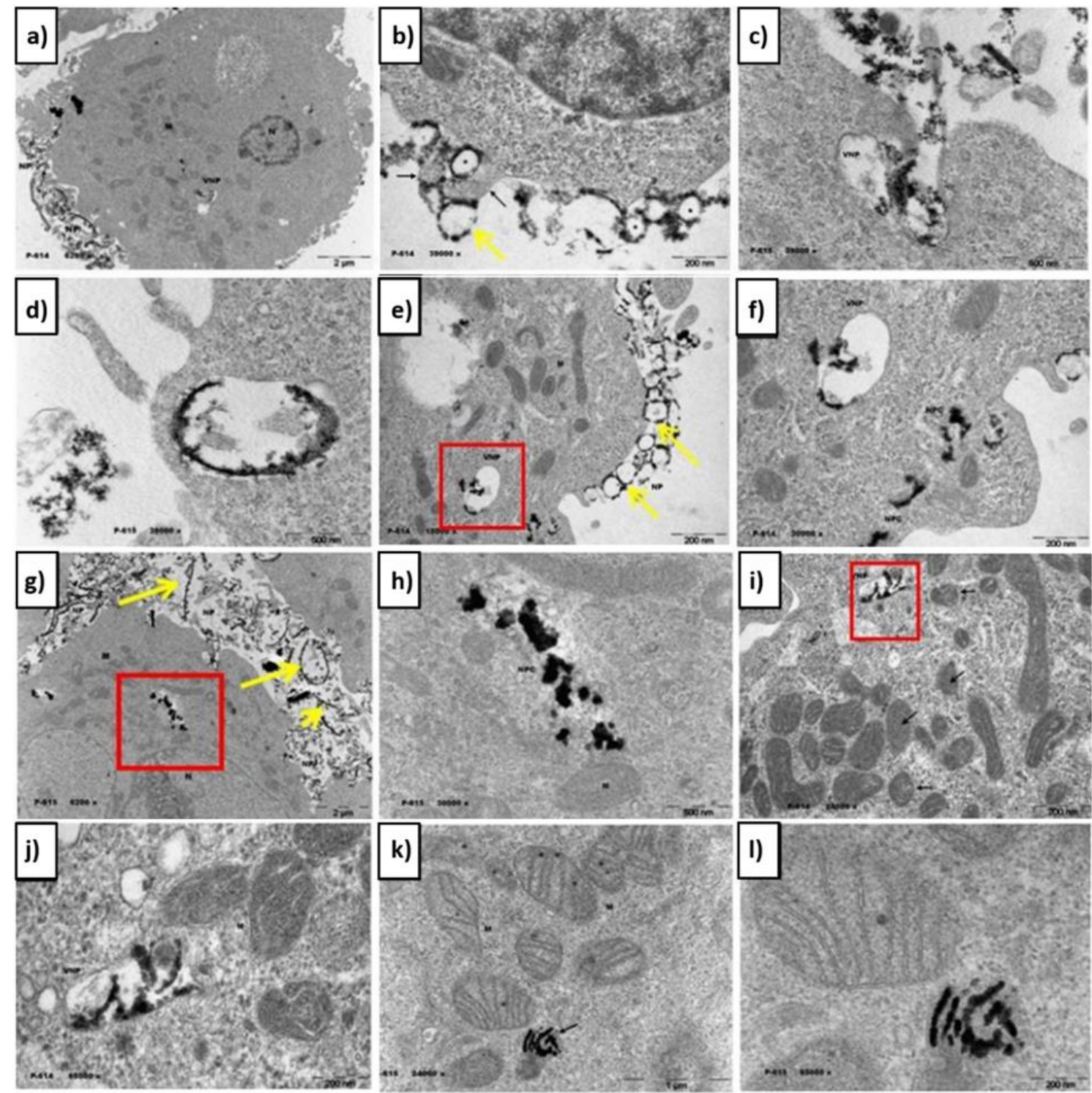

Figure 5:TEM micrographs of SH-DY5Y cells treated with NPt. Nanoparticles surrounding the malignant cell (a) enter the membrane trough vesicle formation (b) and are endocytosed into the cytosol (c), distributed on the luminal face of the vesicle (d). Vesicles travel through the cytosol (e,f) and disintegrate liberating the nanoparticles (g,h,i) which attack mitochondria and the nucleus $(j, k, l)$. Yellow lines indicate the position of the nanoparticles outside the cell. M-mitochondrion. VNP-vesicle with nanoparticles 




Figure 6: Mechanism of endocytosis and catalysis followed by the nanobiocatalyst (NPt) in the malignant cell. A possible ligand-receptor interaction in the plasmatic membrane triggers endocytosis and the NPt enter de cell in vesicles, travel through the intracellular matrix and arrive to the mitochondria and the nucleus, where they carry out catalyst reactions that modify the structure of the DNA causing apoptosis.

nanoparticles, carrying out the catalytic reactions mentioned above. The process is synthesized in Figure 6.

In vivo analysis. Nanoparticles were applied in the pediatric patient with ependymoma following the correspondent ethic statutes of the HIMFG, which has approved the application of this therapy as a compassionate treatment for resilient patients in accordance with the Declaration of Helsinki, ClinicalTrials.gov Identifier: NCT03250520. Ependymomas show histological similarities with the lining cells surrounding the ventricles, with the posterior fossa being the most common location (60-70\%) [33,34]. Its historical classification has been controversial since the differences between classical and anaplastic ependymoma does not represent any benefit from a clinical point of view, nor in the decision-making process [35-37]. The most important prognostic factor to consider a cure is the percentage of surgical resection, $41 \pm 7 \%$ of the patients with partial resection can live without the disease for 3 years in, compared to $73 \pm 4 \%$ of those having a total resection $[38,39]$. There are no randomized studies that demonstrate the benefits of radiotherapy, considering that its response is only partial, observing recurrence in $50 \%$ of all the cases $[39,40]$.

Our patient presented a recurrent classical ependymoma that did not respond to surgical treatment. There are isolated reports that indicate that after the tumor recurrence, it is possible to improve patient's survival with a new radiotherapy cycle, however, in this case no benefit was observed [39,41]. This tumor is resistant to chemotherapy and no adjuvant therapy has brought any benefit to the patient $[40,42]$. Recurrence in most cases is local and with a high mortality, with a 5 years survival from 0 to $25 \%$ [34,41]. A new resection surgery was performed with the removal of $90 \%$ of the tumor. After resection, $3 \mathrm{~g}$ of NPt were placed in the surgical bed before closure. Patient without postoperative complications remains under hospital supervision for 10 days without observing local or systemic adverse effects, clinical and radiological outpatient follow-up on a weekly basis for one month. Follow-up by external consultation continues without complications (Figure 2a). 18F-fluoro-ethyl-Ltyrosine positron emission tomography (18F-FET) was performed 3 months after the placement of NPt in which radiopharmaceutical uptake was not observed (Figure 2b).

After NPt administration in glioblastoma experimental models, tumor reduction has been confirmed $[17,43,44]$. This compound is internalized into cancer cells by endocytosis and produces cell death through apoptotic mechanisms mediated by caspase-3 [45]. So far no adverse effects associated with the use of this nanomaterial have been documented; the cellular mechanism by which it is selectively detected by cancer cells without causing injury to the healthy cells is still under investigation, as the present case demonstrates. The FET-PET study has shown $94 \%$ of sensitivity and $88 \%$ specificity for CNS tumors detection, and it is considered superior to FDGPET for cancer recurrences detection [46,47]. It is essential that the nanoparticle moves directly to the tumor and forms a halo that can be observed by magnetic resonance image as a white circle with a lot of light (Figure 2d). In order to know the role of the nanoparticles in front of the tumor, magnetic resonances were taken every week. It was observed that the nanoparticles were found inside the tumor between the malignant cells at the same time that they closed the ring until the cancerous part was completely saved. We turned to the cat that was marked with that is completely selective to brain tumors what was found was the total disappearance of the tumor. There were scattered nanoparticles on the right side. Floating in the cerebrospinal fluid, these disappear from the organism little by little via the kidneys.

After 6 months of monthly follow-up post-NPt administration no signs or symptoms of tumor recurrence are observed. MRI does not show signs of adverse effects caused by nanobiocatalyst or tumor growth; hematological, pancreatic, renal, and hepatic levels are normal, without alteration. The absence of the radiopharmaceutical and the clinical improvement observed in the patient in terms of facial paralysis and cerebellar syndrome make us consider it a successful case of cancer elimination, as well as a proof of the antineoplastic efficiency of the platinum stabilized in functionalized titania. A new FET-PET analysis is pending in order to confirm cancer absence. Further studies are yet to be carried out to identify the exact mechanism of action of the nanoparticles, specifically regarding the selective endocytosis process.

\section{Conclusion}

In this article we synthesized and characterized a nanostructure compound based on titania and platinum that exhibit antineoplastic properties. The nanoparticles were studied in a cell model to observe their behavior in the intracellular matrix. This analysis showed that the NPt entered the cell through endocytosis and, afterward, attack 
both the mitochondria and the nucleus, where the nanoparticles catalyze the breaking of the $\mathrm{C}-\mathrm{C}$ and $\mathrm{C}-\mathrm{N}$ bonding present in the DNA chain. Our hypothesis is that the functionalization agents present in the nanobiocatalyst develop a ligand-receptor interaction with the receptors in the plasmatic membrane surface of only malignant cells, hence activating the endocytosis. Further studies must be carried out to identify such receptors. This case of tumor elimination through nanobiocatalyst administration demonstrates the importance of continuing research studies in catalytic nanomedicine. We continue with the clinical, radiological, and laboratory follow-up of our patient. Remaining vigilant of recurrence data and the presence of undocumented side effects.

\section{Author Contributions}

All authors have given approval to the final version of the manuscript.

\section{Funding Information}

The Ministry of Health of Mexico City and the Autonomous Metropolitan University supported this research under the registry number 101/100/014/13.

\section{Acknowledgment}

We would like to thank CINVESTAV-Zacatenco, the Western Institute of Technology and Higher Education (ITESO), the Autonomous Metropolitan University - Xochimilco and the CONACYT for their support in this project.

\section{Abbreviations}

NPt: Platinum Stabilized in Functionalized Titania; CNS: Central Nervous System; HIMFG: Hospital Infantil de México "Federico Gómez"; SEM: Scanning Electron Microscopy; TEM: Transmission Electron Microscopy; EDX: Energy-Dispersive X-ray Spectroscopy; XPS: X-ray Photoemission Spectroscopy; MRI: Magnetic Resonance Imaging; 18F-FET: 18F-Fluoro-Ethyl-L-Tyrosine Positron Emission Tomography

\section{References}

1. Alegría-Loyola MA, Galnares-Olalde JA, Mercado M (2017) Tumores del Sistema Nervioso Central. Rev Med Inst Mex Seguro Soc 55: 330-340. [Crossref]

2. Wells EM, Packer RJ (2015) Pediatric Brain Tumors. Contin. Lifelong Learn Neurol 21: 373-396. [Crossref]

3. Grob ST, Levy JMM (2018) Improving Diagnostic and Therapeutic Outcomes in Pediatric Brain Tumors. MolDiagnTher 22: 25-29. [Crossref]

4. Frühwald MC, Rutkowski S (2011) Tumors of the Central Nervous System in Children and Adolescents. DtschArzteblint 108: 390-397. [Crossref]

5. Siegel RL, Miller KD, Jemal A (2016) Cancer Statistics. CA Cancer J Clin 66: 7-30. [Crossref]

6. PoussaintTY, Panigraphy A, Huisman TAGM (2015) Pediatric Brain Tumors. PediatrRadiol 45: 443-453.

7. Back M, Rodríguez M, Jayamanne D, Khasraw M, Lee A, et al. (2016) Understanding the Revised Fourth Edition of the World Health Organization Classification of Tumors of the Central Nervous System (2016) for Clinical Decision-Making: A Guide for Oncologists Managing Patients with Glioma. ClinOncol 30: 556-562. [Crossref]

8. Ostrom QT, Gittleman H, Liao P, Vecchione-Koval T, YingliWolinsky, et al. (2017) CBTRUS Statistical Report: Primary Brain and Other Central Nervous System
Tumors Diagnosed in the United States in 2010-2014. Neuro Oncol 19: v1-v88. [Crossref]

9. De la Torre-Mondragón L, Ridaura-Sanz C, Reyes-Mujica M, Rueda-Franco F (1993) Central Nervous System Tumors in Mexican Children. Child's NervSyst 9: 260-265. [Crossref]

10. Chico-Ponce-de-León F, Castro-Sierra E, Perezpeña-Diazconti M (2006) Tumores Intracraneanos Del Niño. Bol Med Hosp Infant Mex 63: 367-381.

11. Burzynski SR (2006) Treatments for Astrocytic Tumors in Children. Paediatric Drugs 8: 167-178. [Crossref]

12. Dilruba S, Kalayda GV (2016) Platinum-Based Drugs: Past, Present and Future. Cancer ChemotherPharmacol 77: 1103-1124. [Crossref]

13. Riddell IA, Lippard SJ (2018) Cisplatin and Oxaliplatin: Our Current Understanding of Their Actions. Met Ions Life Sci 18: 1-42. [Crossref]

14. O'Dwyer PJ, Stevenson JP, Johnson SW (1999) Clinical Status of Cisplatin, Carboplatin and Other Platinum-Based Antitumor Drugs. In: Cisplatin: Chemistry and Biochemistry of a Leading Anticancer Drug; Lippert B (eds.). Zurich: WileyVCH 29-70.

15. López-Goerne TM (2013) Nanomedicina Catalítica: Ciencia y Cáncer (1st ed.). Mexico City: Arkhé Ediciones 149-156.

16. Caruso G, Merlo L, Tot E, Pignataro C (2017) Nanotechnology and the New Frontiers of Drug Delivery in Cerebral Gliomas. In: Nano and Microscale Drug Delivery Systems; Grumezescu AM, (eds.). Amsterdam: Elsevier 95-107.

17. López T, Álvarez M, González RD, Uddin MJ, Bustos J, et al. (2011) Synthesis, Characterization and In vitro Cytotoxicity of Pt-TiO2 Nanoparticles. Adsorption 17: 573-581. [Crossref]

18. López T, Cuevas JL, Ilharco L, Ramírez P (2018) XPS characterization and E. Coli DNA degradation Using Functionalized Cu/TiO2 Nanobiocatalysts. MolCatal 449: $62-71$.

19. Erdem B, Hunsicker RA, Simmons GW, Sudol ED, Dimonie VL, et al. (2001) XPS and FTIR Surface Characterization of TiO2 Particles Used in Polymer Encapsulation. Langmuir 17: 2664-2669.

20. Beamson G, Briggs D (1992) High Resolution XPS or Organic Polymers. Chichester: The Scienta ESCA 300 Database.

21. Rieger R, Michaelis A, Green MM (1991) Glossary of Genetics. Classical and Molecular (5th ed.). Berlin: Springer-Verlag.

22. Chou LYT, Ming K, Chan WCW (2011) Strategies for the Intracellular Delivery of Nanoparticles. ChemSoc Rev 40: 233-245. [Crossref]

23. You CC, Miranda OR, Gider B, Ghosh PS, Ik-Bum Kim, et al. (2007) Detection and Identification of Proteins Using Nanoparticle-Fluorescent Polymer 'Chemical Nose' Sensors. Nat Nanotechnol 2: 318-323.[Crossref]

24. Jiang Y, Zhao H, Lin Y, Zhu N, Ma Y, et al. (2010) Colorimetric Detection of Glucose in Rat Brain Using Gold Nanoparticles. Angew ChemInt Ed Engl 49: 4800-4804. [Crossref]

25. Saha K, Bajaj A, Duncan B, Rotello VM (2011) Beauty Is Skin Deep: A Surface Monolayer Perspective on Nanoparticle Interactions with Cells and BioMacromolecules. Small 7: 1903-1918. [Crossref]

26. López T, Larraza P, Gómez E (2017) Platinum and Copper Supported in Functionalized Titania Nanoparticles for the Treatment of Cervical and Prostate Cancer. J NanomaterMolNanotechnol 6: 4.

27. López T, Ortiz-Islas E, Guevara P, Gómez E (2013) Catalytic Nanomedicine Technology: Copper Complexes Loaded on Titania Nanomaterias as Cytotoxic Agents of Cancer Cell. Int J Nanomed 8: 581-592. [Crossref]

28. Matsumura Y, Maeda H (1986) A New Concept for Macromolecular Therapeutics in Cancer Chemotherapy: Mechanism of Tumoritropic Accumulation of Proteins and the Antitumor Agent Smancs. Cancer Res 46: 6387-6392. [Crossref]

29. Duncan R, Sat YN (1998) Tumor Targeting by Enhanced Permeability and Retention (EPR) Effect. Ann Oncol 9: 39.

30. Vasey PA, Kaye SB, Morrison R, Twelves C, Wilson P, et al. (1999) Phase I Clinical and Pharmacokinetic Study of PK1 [N-(2-hydroxypropyl) methacrylamide Copolymer Doxorubicin]: First Member of a New Class of Chemotherapeutic Agents-DrugPolymer Conjugates. Cancer Research Campaign Phase I/II Committee. Clin Cancer Res 5: 83-94. [Crossref] 
31. Park J, Choi Y, Chang H, Um W, Ryu J, et al. (2019) Alliance with EPR Effect: Combined Strategies to Improve the EPR Effect in the Tumor Microenvironment. Theranostics 9: 8073-8090. [Crossref]

32. Norbury CJ, Zhivotovsky B (2004) DNA Damage-Induced Apoptosis. Oncogene 23: 2797-2808. [Crossref]

33. Baig MA, Klein JP, Mechtler LL (2016) Imaging of Brain Tumors. Contin. Lifelong Learn Neurol 22: 1529-1552. [Crossref]

34. Zacharoulis S, Moreno L (2009) Ependymoma: An Update. J Child Neurol 24: 14311438. [Crossref]

35. Pajtler KW, Mack SC, Ramaswamy V, Smith CA, Hendrik Witt, et al. (2017) The Current Consensus on the Clinical Management of Intracranial Ependymoma and Its Distinct Molecular Variants. Acta Neuropathol 133: 5-12. [Crossref]

36. Gupta K, Salunke P (2017) Understanding Ependymoma Oncogenesis: An Update on Recent Molecular Advances and Current Perspectives. Mol Neurobiol 54: 15-21. [Crossref]

37. Andreioulo F, Ferreira C, Puget S, Grill J (2013) Current and Evolving Knowledge of Prognostic Factors for Pediatric Ependymomas. Future Oncol 9: 183-191. [Crossref]

38. Gajjar A, Packer RJ, Foreman NK, Cohen K, Daphne Haas-Kogan, et al. (2013) Children's Oncology Group's 2013 Blueprint for Research: Central Nervous System Tumors. Pediatr Blood Cancer 60: 1022-1026. [Crossref]

39. Khatua S, Ramaswamy V, Bouffet E (2017) Current Therapy and the Evolving Molecular Landscape of Paediatric Ependymoma. Eur J Cancer 70: 34-41. [Crossref]
40. Kline C, Forester C, Banerjee A (2017) Ependymoma. In Pediatric CNS Tumors Gupta N, Banerjee A, Haas-Kogan DA (eds.). Cham: Springer International Publishing 69-92.

41. Conter C, Carrie C, Bernier V, Geoffray A, Anne Pagnier, et al. (2009) Intracranial Ependymomas in Children: Society of Pediatric Oncology Experience with Postoperative Hyperfractionated Local Radiotherapy. Int J Radiat Oncol Biol Phys 74: 1536-1542. [Crossref]

42. Bouffet E, Capra M, Bartels U (2009) Salvage Chemotherapy for Metastatic and Recurrent Ependymoma of Childhood. Child's Nerv Syst 25: 1293-1301. [Crossref]

43. López T, Recillas S, Guevara P, Sotelo J, M Alvarez, et al. (2008) Pt/TiO2 Brain Biocompatible Nanoparticles: GBM Treatment Using the C6 Model in Wistar Rats. Acta Biomater 4: 2037-2044. [Crossref]

44. Álvarez-Lemus M, López-Goerne T (2012) Nanotecnología y Cáncer: Aplicación al Tratamiento de TumoresCerebrales. Arch Neurociencias 17: 102-109.

45. Álvarez-Lemus MA, Monroy H, López T, De la Cruz-Hernández EN, Rosendo López- González (2016) Effect of Surface Modification on the Bioactivity of Sol-Gel TiO2-Based Nanomaterials. J Chem Technol Biotechnol 91: 2148-2155.

46. Langen KJ, Galldiks N, Hattingen E, Shah NJ (2017) Advances in Neuro-Oncology Imaging. Nat Rev Neurol 13: 279-289. [Crossref]

47. Dunet V, Pomoni, A, Hottinger A, Nicod-Lalonde M, John O Prior (2016) Performance of 18F-FET Versus 18F-FDG-PET for the Diagnosis and Grading of Brain Tumors: Systematic Review and Meta-Analysis. Neuro Oncol 18: 426-434 [Crossref]

\section{Citation:}

López-Goerne TM, Padilla-Godinez FJ, Álvarez D, Gómez E, Ramírez P, et al. (2020) Titania-Platinum Nanobiocatalyst as Treatment for Central Nervous System Tumors: A Case Report on a Pediatric Ependymoma. J Neurol Neurocrit Care Volume 3(1): 1-8. 